\title{
Individual Differences in Cocaine-induced Locomotor Activity in Rats: Behavioral Characteristics, Cocaine Pharmacokinetics, and the Dopamine Transporter
}

\author{
Joshua M Gulley*,', Brian R Hoover', Gaynor A Larson' and Nancy R Zahniser' \\ 'Department of Pharmacology and Neuroscience Program, University of Colorado Health Sciences Center, Denver, CO, USA
}

\begin{abstract}
Outbred male Sprague-Dawley rats can be classified as either low or high cocaine responders (LCRs or HCRs, respectively) based on their locomotor response to acute cocaine. Concomitant measurement of dopamine clearance in these rats revealed that the differential behavioral responses are associated with the magnitude of dopamine transporter (DAT) inhibition by cocaine. Here, we investigated several factors that might contribute to cocaine-induced behavioral variability and its association with differential inhibition of DAT function. In rats classified as LCRs or HCRs after $10 \mathrm{mg} / \mathrm{kg}$ cocaine injection, we found no differences in (I) novelty-induced locomotion, (2) cocaine levels in dorsal striatum or nucleus accumbens (NAc), (3) DAT number or affinity in NAc, or (4) DAT affinity for cocaine in NAc. In rats given $20 \mathrm{mg} / \mathrm{kg}$ cocaine, behavior was more uniform across individuals, but still warranted separation into LCR/HCR categories. Additionally, we analyzed the stability of the LCR/HCR classification made during the first test with 10 or $20 \mathrm{mg} / \mathrm{kg}$ cocaine by retesting rats 7 days later with saline or cocaine ( 10 or $20 \mathrm{mg} / \mathrm{kg}$ ). Before injection, HCRs were more active relative to LCRs and to their own behavior on the first test day. Following cocaine, LCRs and HCRs exhibited similar drug-induced changes in locomotion, but there were unique effects that depended on the cocaine dose given on the first and second test days. Our results argue against several likely explanations for individual differences in cocaine-induced behavior and highlight the influence of a single cocaine exposure on subsequent behavioral responses to the drug.
\end{abstract}

Neuropsychopharmacology (2003) 28, 2089-2I0I, advance online publication, 6 August 2003; doi: 10.1 038/s.npp. 1300279

Keywords: individuality; psychostimulants; exploratory behavior; cocaine; dopamine transporter; rats

\section{INTRODUCTION}

Psychomotor stimulants, such as amphetamine and cocaine, produce behavioral effects that are characterized by significant variability among individuals (Segal and Schuckit, 1983; de Wit et al, 1986; Piazza and Le Moal, 1996). In rodents, this variability is seen in rats self-administering these drugs (Piazza et al, 1989, 2000; DeSousa et al, 2000) and in those injected either acutely (Segal and Kuczenski, 1987; Deminiere et al, 1989; Hooks et al, 1991b; Sabeti et al, 2002) or repeatedly (Post et al, 1988; Piazza et al, 1989; Hooks et al, 1991a; Sabeti et al, 2003). Indeed, up to half the rats in a sensitization paradigm utilizing repeated cocaine or amphetamine treatment fail to exhibit augmented locomotor responses following drug challenge (Segal and Kuczenski, 1987; Camp and Robinson, 1988; Mayfield et al, 1992; Cass et al, 1993; Pierce et al, 1996).

\footnotetext{
*Correspondence: Dr Joshua M Gulley, Department of Pharmacology, University of Colorado Health Sciences Center, Campus Box C-236, 4200 E Ninth Avenue, Denver, CO 80262, USA, Tel: 00I (303) 3I56638, Fax: 00I (303) 315-7097, E-mail: joshua.gulley@uchsc.edu

Received 07 May 2003; revised 18 June 2003; accepted 20 June 2003 Online publication: 25 June 2003 at http://www.acnp.org/citations/ Npp0625030320 I/default.pdf
}

A rat's response to a novel environment can be an important predictor of its response to psychostimulant drugs (Piazza et al, 1989; Hooks et al, 1991b; Bardo et al, 1996). Multiple studies suggest that nigrostriatal and mesolimbic dopamine (DA) systems terminating in the dorsal striatum (dSTR) and nucleus accumbens (NAc), respectively, are relatively overactive in high responders to novelty (HRs) compared to low responders (LRs; Bradberry et al, 1991; Piazza et al, 1991b; Hooks et al, 1994; Marinelli and White, 2000). For example, a recent study utilizing nonet-flux microdialysis demonstrated that, compared to LRs, HRs exhibit greater locomotor sensitization after repeated injections with $20 \mathrm{mg} / \mathrm{kg}$ cocaine and have both reduced basal DA uptake and greater cocaine-induced inhibition of uptake in the NAc (Chefer et al, 2003).

Another indicator of individual differences in psychostimulant drug response is the magnitude of an animal's behavioral response to the initial drug exposure (Segal and Schuckit, 1983). Recently, our laboratory found that outbred male Sprague-Dawley rats can be classified as either low or high cocaine responders (LCRs or HCRs, respectively) based on their locomotor response to a single, low dose of cocaine $(10 \mathrm{mg} / \mathrm{kg}$, i.p.; Sabeti et al, 2002). Specifically, those animals with activity scores below the 
distribution median were defined as LCRs, while those with scores above it were HCRs. Individual differences in the behavioral response to cocaine may be due to a number of underlying mechanisms (Robinson, 1988). However, by simultaneously measuring behavior and exogenous DA clearance, we showed that variation in the function of one of cocaine's primary cellular targets - the dopamine transporter (DAT) - plays a significant role (Sabeti et al, 2002). In contrast to minimal differences in baseline DAT function in LCRs and HCRs, $10 \mathrm{mg} / \mathrm{kg}$ cocaine reduced DA clearance only in the NAc of HCRs. Furthermore, over successive treatment days with cocaine, locomotor sensitization developed in LCRs and was associated with an increased ability of cocaine to inhibit DA clearance (Sabeti et al, 2003). In HCRs, there was no evidence of locomotor sensitization and this was paralleled by a lack of change in cocaine-induced inhibition of DAT function.

In the present study, we further investigated these individual differences in cocaine-induced behavior. First, we extended our original observations (Sabeti et al, 2002, 2003) by characterizing the acute behavioral responses of a large sample of outbred male Sprague-Dawley rats to $10 \mathrm{mg} / \mathrm{kg}$ cocaine and also testing the extent to which a higher, acute dose of cocaine $(20 \mathrm{mg} / \mathrm{kg})$ could be used to classify rats as LCRs and HCRs. We next tested the hypothesis that differential locomotor activation in LCRs, compared to HCRs, is due to disparities in cocaine pharmacokinetics by measuring levels of cocaine in dSTR and NAc. A putative mechanism underlying the relationship between DAT function and cocaine-induced locomotor activation was evaluated by testing for differences in the number and/or affinity of DAT binding sites or their affinity for cocaine in the NAc of LCRs vs HCRs. Lastly, our previous studies indicated that repeated cocaine treatment results in locomotor sensitization in LCRs, but not HCRs (Sabeti et al, 2003). However, it was unclear if, in the absence of repeated treatment, the differences in locomotor activation between LCRs and HCRs observed with acute cocaine persist. Furthermore, it was not known if LCRs and HCRs would have proportional increases in behavior if given a higher dose of cocaine. To address these questions, we analyzed behavior in LCRs and HCRs induced by an injection of saline or cocaine $(10$ or $20 \mathrm{mg} /$ $\mathrm{kg}) 7$ days after the initial exposure to 10 or $20 \mathrm{mg} / \mathrm{kg}$ cocaine.

\section{MATERIALS AND METHODS}

\section{Animals}

Outbred, male Sprague-Dawley rats (2-4 months of age) were obtained from Charles Rivers Laboratory (Sasco, Omaha, NE) and housed up to three per cage with a 12-h light/dark cycle and unrestricted access to food and water. Rats were brought to the laboratory on the day of the initial behavioral characterization, individually housed, and allowed to habituate to the environment for $1-4 \mathrm{~h}$ before testing. All animal use procedures were in accordance with the NIH Guide for the Care and Use of Laboratory Animals and were approved by the Institutional Animal Care and
Use Committee at the University of Colorado Health Sciences Center.

\section{Initial Behavioral Characterization}

Rats were placed in an open-field activity apparatus consisting of a clear acrylic box $(16 \times 16 \times 15$ in $)$ fitted with a photo beam frame (eight beams per dimension; San Diego Instruments, San Diego, CA). The apparatus was located within a sound-attenuating cubicle $(2 \times 2 \times 2 \mathrm{ft})$ that contained a ceiling-mounted white light $(4 \mathrm{~W})$ and a door with a Plexiglas window. After a 1.5-h habituation period, rats were removed from the apparatus, injected (i.p.) with 10 or $20 \mathrm{mg} / \mathrm{kg}(-)$ cocaine $\mathrm{HCl}$ ( $n=92$ and 20, respectively), and returned to the apparatus for $1 \mathrm{~h}$.

Throughout the test session, locomotor behavior was recorded as consecutive, horizontal photo beam breaks and subsequently converted by computer to distance traveled (cm) per 1-min interval. Rats with activity scores during the 30 min after cocaine injection that fell below the distribution median were defined as LCRs, while those with scores above the median were defined as HCRs. In addition to locomotor activity, the behavior of some rats (behavior retest group; see below) was scored by an observer who viewed the test session as it occurred or on videotape. Observers, who were unaware whether rats were characterized as LCRs or HCRs, scored behavior in 60-s intervals for the $30 \mathrm{~min}$ before and $1 \mathrm{~h}$ after injection using the following categories: 'nonmovement,' defined as inactivity or sleeping; 'grooming,' defined as movements directed against self that typically include forepaw movements over the body, scratching, licking, body gnawing, and face washing; 'head movement/sniffing,' defined as movements of the head and/ or sniffing that occurred in the presence of discrete upper or lower body movements but in the absence of locomotion; 'exploring,' defined as locomotion around the activity chamber that was continuous or occurred in repeated bouts and typically includes head movements and sniffing; 'stereotypy,' defined as repetitive head movements and sniffing, head bobs, and/or side-to-side head sways that were directed at the environment and were confined to a small area of the chamber; and 'rearing,' defined as the lifting of both forepaws off the floor with posture maintained on the hind legs. With the exception of rearing, behaviors were scored on a binary scale $(0=$ absent; $1=$ present), with those expressed for at least 10 consecutive seconds of a 60-s interval scored as present (Fray et al, 1980; Sabeti et al, 2002). In cases where no single behavior persisted for $10 \mathrm{~s}$, the behavior expressed during the majority of the 60-s interval was considered present.

At the conclusion of the test session, rats were returned to their home cage where they were allowed unrestricted access to food and water. They remained in the experimental test room for 7 additional days, during which time they were maintained on a 12-h light/dark cycle. A total of 7 days were allowed to elapse between the initial behavioral characterization and subsequent experiments in order to minimize the influence of any residual drug effects. On day 8 , rats initially characterized with $10 \mathrm{mg} / \mathrm{kg}$ cocaine were pseudorandomly chosen for radioligand binding or behavior retest experiments (see below), while all rats initially 
characterized with $20 \mathrm{mg} / \mathrm{kg}$ were used in behavior retest experiments.

\section{High-performance Liquid Chromatography (HPLC)}

In a separate group of rats $(n=26)$, we measured brain levels of cocaine using reverse-phase HPLC coupled with ultraviolet detection (Benuck et al, 1987; Cass and Zahniser, 1993). These rats underwent the same procedure for behavioral testing as described above, except they were removed from the activity apparatus $30 \mathrm{~min}$ after i.p. injection with $10 \mathrm{mg} / \mathrm{kg}$ cocaine. They were killed by decapitation between 30 and 31 min postinjection, their brains were rapidly removed, and the dSTR and NAc from both sides of the brain were dissected in an ice bath using a vibratome and manual dissection. Brain tissue was weighed (mean \pm SEM for dSTR: $49.2 \pm 1.50 \mathrm{mg}$; NAc: $33.6 \pm 1.48 \mathrm{mg})$ and frozen $\left(-80^{\circ} \mathrm{C}\right)$ for up to 1 week. For analysis, tissue was sonicated in $300 \mu \mathrm{l}$ acetonitrile and $20 \mu \mathrm{l}$ of the internal standard cocaine propyl ester- $\mathrm{HCl}$ (CPE; $30 \mathrm{ng} / \mathrm{ml}$ ). Following centrifugation, the supernatant was mixed with $350 \mu \mathrm{l}$ of chloroform: ethanol $(4: 1)$ and $50 \mu \mathrm{l}$ $0.1 \mathrm{M} \mathrm{NaHCO}$ and recentrifuged. The lower organic layer

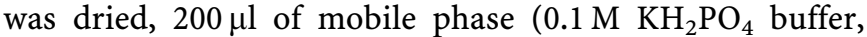
$\mathrm{pH}=2.7$, and $40 \%$ acetonitrile) was added, and $100 \mu$ of the resulting solution was injected into the HPLC system where separation was accomplished using a Keystone-Hypersil ODS $3 \mu \mathrm{m}$ particle column $(100 \mathrm{~mm} \times 4.6 \mathrm{~mm})$ at room temperature. The flow rate was $1.7 \mathrm{ml} / \mathrm{min}$ and absorbance was monitored at $235 \mathrm{~nm}$.

\section{Radioligand Binding}

The number and affinity of DAT binding sites and the affinity of DAT for cocaine were assessed in NAC membranes using indirect $\left[{ }^{3} \mathrm{H}\right]$ WIN 35,428 saturation and cocaine competition binding assays, respectively (modified from Hebert et al, 1999). At 7 days after their initial behavioral characterization with $10 \mathrm{mg} / \mathrm{kg}$ cocaine, rats $(n=33)$ were decapitated and two, $1-\mathrm{mm}$ thick NAc sections $(+1.74$ to $-0.26 \mathrm{~mm}$ around bregma) were isolated, placed in $1 \mathrm{ml}$ of ice-cold assay buffer $(30 \mathrm{mM}$ $\mathrm{NaH}_{2} \mathrm{PO}_{4}, 15 \mathrm{mM} \mathrm{Na} \mathrm{HPO}_{4}$, and $0.32 \mathrm{M}$ sucrose; $\mathrm{pH} 7.4$ ), and homogenized for $20 \mathrm{~s}$. For the indirect saturation studies, samples were centrifuged $(20000 \mathrm{~g}$ for $20 \mathrm{~min}$ at $4{ }^{\circ} \mathrm{C}$ ) to obtain a pellet, which was resuspended, rehomogenized, and then incubated on ice in duplicate samples for $1 \mathrm{~h}$ with $5 \mathrm{nM}\left[{ }^{3} \mathrm{H}\right] \mathrm{WIN} 35,428$ and 10 increasing concentrations of unlabeled WIN 35,428 (range $=0.3 \mathrm{nM}-3 \mu \mathrm{M}$ ). Total and nonspecific binding was defined in the absence or presence of $30 \mu \mathrm{M}$ benztropine mesylate, respectively. Incubation was terminated via rapid vacuum filtration through GF/B filters (Brandel, Gaithersburg, MD) followed by two, 3-ml washes with ice-cold assay buffer. Radioactivity was quantified $24-48 \mathrm{~h}$ later by liquid scintillation spectroscopy. Protein content was determined (Bradford, 1976) using bovine serum albumin as the standard. For the cocaine competition assays, we used procedures identical to those described above, except 10 increasing concentrations of cocaine were substituted for unlabeled WIN 35,428 (range $=3-100 \mathrm{nM}$ ).

\section{Behavior Retest}

Rats in the behavior retest group were placed back into the activity apparatus on day 8 at approximately the same time of day as on day 1 . As on test day 1 , they were allowed to habituate for $1.5 \mathrm{~h}$ before they were given an injection. Rats given $10 \mathrm{mg} / \mathrm{kg}$ cocaine on day 1 were injected (i.p.) with either saline or cocaine $(10$ or $20 \mathrm{mg} / \mathrm{kg}$ ) and those given $20 \mathrm{mg} / \mathrm{kg}$ cocaine on day 1 were injected (i.p.) with $20 \mathrm{mg} / \mathrm{kg}$ cocaine. Behavior was monitored for an additional $1 \mathrm{~h}$ using both automated and observational methods (see above).

\section{Statistical Analysis}

Unless otherwise noted, data are presented as mean \pm SEM. Locomotor activity scores were averaged into 15 -min bins. Rearing was tabulated as the total number of occurrences during a 60-s interval and summed into 15-min bins. Incidence scores for the remaining behavioral observation categories were summed into 15 -min bins and transformed into a frequency score by dividing the cumulative score by 15. Differences between groups (ie LCRs and HCRs) were analyzed using a mixed, two-factor ANOVA (group $\times$ time, with time as the repeated measure) followed by pairwise comparisons of specific time points using the Holm-Sidak method (SigmaStat 3.0; SPSS, Inc., Chicago, IL). For comparisons between the first and second behavioral test days, locomotor and observational data were averaged into 30 - or 60 -min bins and analyzed using either paired $t$-tests or repeated measures ANOVA followed by Holm-Sidak post hoc tests.

HPLC data were analyzed using two-factor ANOVA (group $\times$ brain region) to evaluate overall differences and linear regression to evaluate the relationship between cocaine levels and locomotor activation. Radioligand binding data were analyzed with nonlinear curve fitting for one- or two-site binding models to obtain $\mathrm{IC}_{50}$ and $K_{\mathrm{i}}$ values (GraphPad Prism, GraphPad Software, Inc., San Diego, CA). $B_{\max }$ values were derived using the formula described by DeBlasi et al (1989). Differences in specific binding of $\left[{ }^{3} \mathrm{H}\right]$ WIN 35,428 were analyzed by two-way ANOVA (group $\times$ drug concentration), while differences in $K_{\mathrm{i}}$ and $B_{\max }$ were analyzed with Student's $t$-test.

\section{Materials}

Chemicals were purchased from Sigma (St Louis, MO) or Fisher (Pittsburgh, PA), with the following exceptions: $\left[{ }^{3} \mathrm{H}\right]$ WIN 35,428 was purchased from NEN Life Science Products (Boston, MA) and (-)cocaine $\mathrm{HCl}$ was obtained from the National Institute on Drug Abuse (RTI International, Research Triangle Park, NC).

\section{RESULTS}

\section{Acute Behavioral Response to Cocaine}

We have shown previously that a single i.p. injection of $10 \mathrm{mg} / \mathrm{kg}$ cocaine leads to variable changes in locomotor activity in outbred male, Sprague-Dawley rats and that these rats can be classified as either LCRs or HCRs based on the total distance traveled during the first $30 \mathrm{~min}$ after 
injection (Sabeti et al, 2002). In the relatively large sample studied here $(n=92)$, we found similar results: a narrow distribution of baseline locomotor activity (Figure 1a) and a broad distribution of locomotor activation after $10 \mathrm{mg} / \mathrm{kg}$ cocaine (Figure 1b). During the $30 \mathrm{~min}$ before and after injection with this dose, the mean $( \pm S D)$ locomotor activity was $2035 \pm 2068$ and $9523 \pm 4637 \mathrm{~cm}$, respectively. When the distribution was divided using the postinjection median score of $9227 \mathrm{~cm} / 30 \mathrm{~min}$, the mean $( \pm S D)$ values for LCRs and HCRs before injection were $1991 \pm 2039$ and $2080 \pm 2118 \mathrm{~cm} / 30 \mathrm{~min}$, respectively. After injection, LCRs increased locomotion to $5544 \pm 2274 \mathrm{~cm} / 30 \mathrm{~min}$, while HCRs increased to $13501 \pm 2441 \mathrm{~cm} / 30 \mathrm{~min}$. Splitting the distribution into LCRs and HCRs was supported by multiple component analysis of locomotor activity during the $30 \mathrm{~min}$ following injection, which confirmed the existence of two components (LCR proportion $=49 \%$; $\mathrm{HCR}$ proportion $=51 \% ; p<0.01$, NOCOM analysis; Ott, 1979; Sabeti et al, 2002).

While the locomotor behavior of LCRs and HCRs was not different during the habituation period, $10 \mathrm{mg} / \mathrm{kg}$ cocaine increased locomotion in both groups (Figure 1c). There were significant main effects of group and time $\left(\mathrm{F}_{1,90}=61.3\right.$, $p<0.001$ and $\mathrm{F}_{9,810}=309.0, p<0.001$, respectively) and a significant group $\times$ time interaction $\left(\mathrm{F}_{9,810}=28.6\right.$, $p<0.001)$. Furthermore, observational analysis of behavior indicated several notable differences between LCRs and HCRs in the behavior induced by $10 \mathrm{mg} / \mathrm{kg}$ cocaine (Figure 2). Compared to the $30-\mathrm{min}$ period before injection (ie baseline), LCRs spent more time after cocaine in periods of nonmovement and head movement/sniffing than HCRs (Figure $2 \mathrm{a}$ and $\mathrm{b}$ ), which engaged more in exploring and rearing behaviors (Figure $2 \mathrm{c}$ and $\mathrm{d}$ ). Neither group exhibited increases in grooming or stereotypy (data not shown).

Since locomotor response to a novel environment has been shown to be predictive of subsequent psychostimulant self-administration and behavioral sensitization (Piazza et al, 1989; Hooks et al, 1991b; Bardo et al, 1996), we recharacterized our rats as having either a low or high locomotor response to novelty (LR or HR, respectively) based on their activity during the first $30 \mathrm{~min}$ spent in the open-field apparatus. Those rats with scores below the

Figure I Individual differences in the locomotor activity of outbred, male Sprague-Dawley rats before and after injection of $10 \mathrm{mg} / \mathrm{kg}$ cocaine on test day 1 . Animals were placed in a locomotor activity apparatus for $90 \mathrm{~min}$, injected with cocaine, and returned to the apparatus for $60 \mathrm{~min}$. Frequency distributions of cumulative locomotor activity for the $30 \mathrm{~min}$ before and after drug injection are shown in (a) and (b), respectively. Most rats were relatively inactive before injection, whereas cocaine led to a wide distribution of locomotor responses. Rats with cocaine-induced activity scores below the median $(9227 \mathrm{~cm} / 30 \mathrm{~min}$; dotted line in b) were considered LCRs and those with scores above it were HCRs. The mean \pm SEM locomotor responses of LCRs and HCRs over the course of the experiment are shown in (c) ( $n=46 /$ group; arrow = time of injection). $* p<0.05$, within-group comparison to the 15 -min period before injection; $\#_{p}<0.05$, compared to LCRs in the same I5-min interval. (d) When rats were recharacterized as having either a low or high novelty response during the first 30 min of their exposure to the open-field chamber (LR or HR, respectively), there were significant differences in cocaine-induced locomotor activity only during the 15-min period following drug injection. $* p<0.05$, within-group comparison to the 15 -min period before injection; $\# p<0.05$, compared to LRs in the same I5-min interval. median of $13674 \mathrm{~cm} / 30 \mathrm{~min}$ were considered to be LRs and those above the median were HRs. Following $10 \mathrm{mg} / \mathrm{kg}$ cocaine, locomotor behavior was increased significantly in both groups (Figure 1d). For the 30-min period following injection, the mean $( \pm S D)$ distance traveled in LRs and HRs was $8983 \pm 4795$ and $10060 \pm 4461 \mathrm{~cm}$, respectively. With the exception of the 15 -min period immediately following injection, there were no differences in cocaineinduced activity when rats were separated into LRs and HRs.

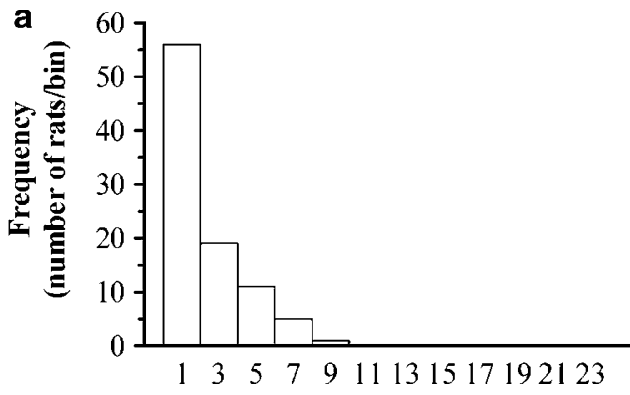

Distance Traveled $\left(x_{10}^{3} \mathrm{~cm} / 30 \mathrm{~min}\right)$

b

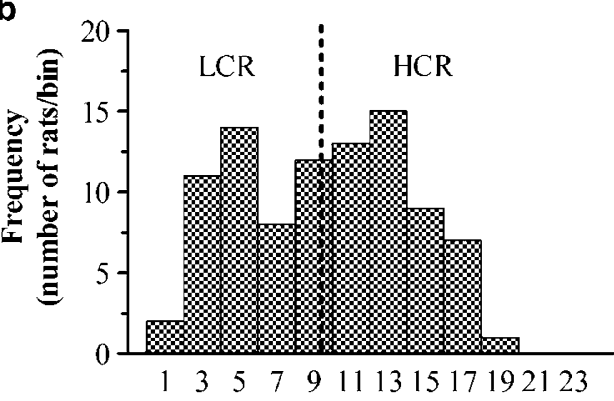

Distance Traveled (x $\left.10^{3} \mathrm{~cm} / 30 \mathrm{~min}\right)$

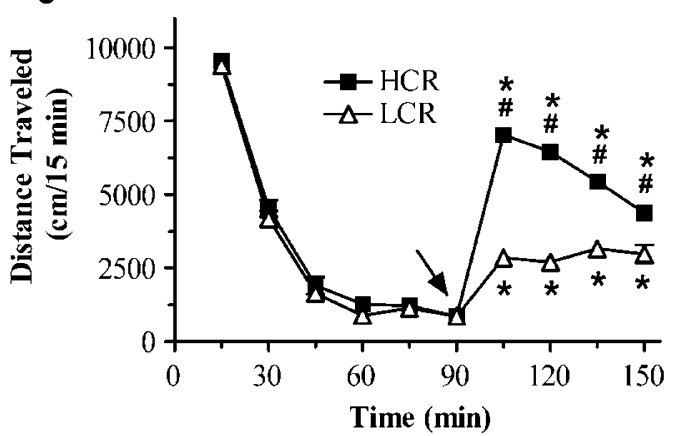

d

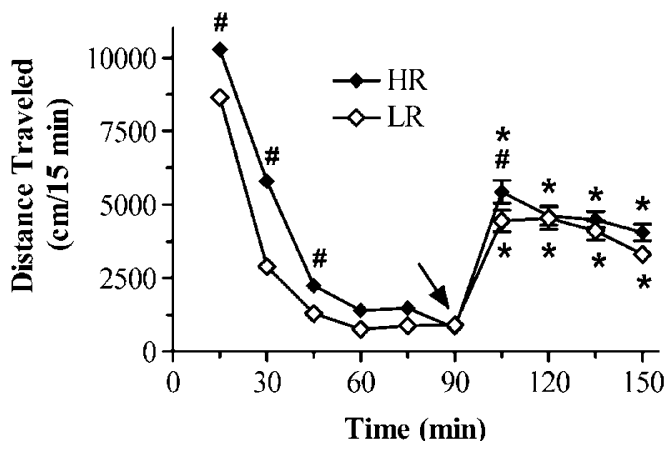



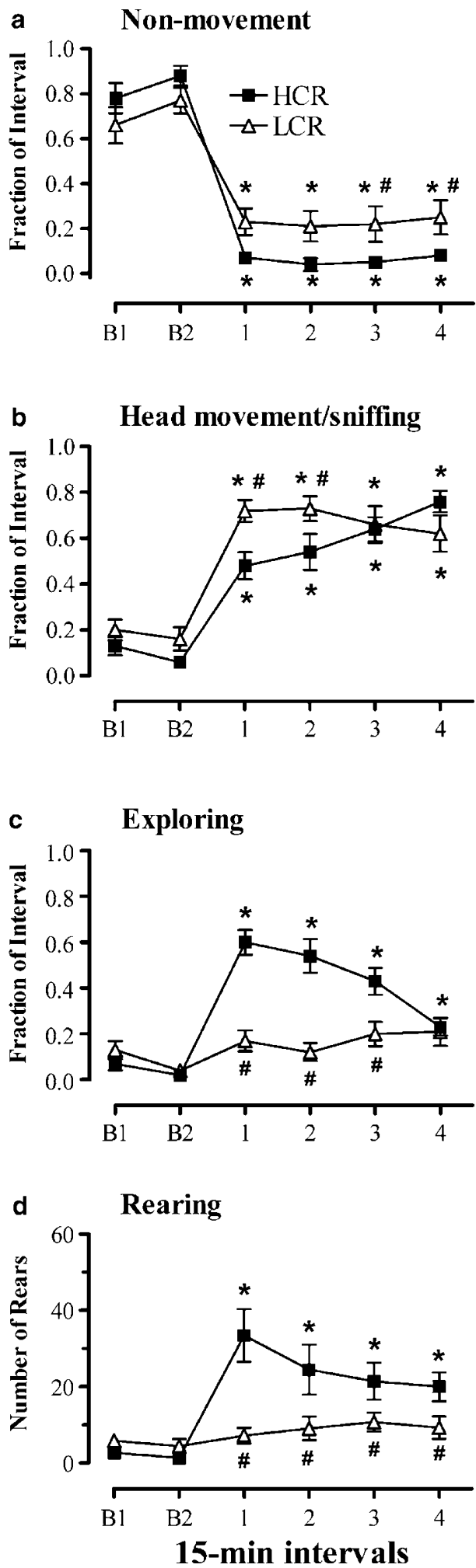

Figure 2 Observational analysis of behavior on test day I revealed unique effects of $10 \mathrm{mg} / \mathrm{kg}$ cocaine in LCRs compared to HCRs (characterized in Figure I). The I5-min intervals before (BI and B2) and after $(1-4)$ drug injection are shown. With the exception of rearing, data are presented as the fraction of the 15-min interval that rats were engaged in the behavior specified (see Materials and methods). A value of I.0, for example, would indicate that the rat was engaged in the behavior during each of the 60-s scoring periods within an interval. Rearing data are the total number of rears during each 15-min interval. $* p<0.05$, within-group comparison to B2; ${ }^{*} p<0.05$, compared to HCRs in the same time interval.
In a separate group of rats $(n=20)$, we tested whether a higher dose of cocaine would also lead to a broad distribution of locomotor activation. Relative to the effects of $10 \mathrm{mg} / \mathrm{kg}$ cocaine, the frequency distribution of locomotor scores before injection was similar, but after $20 \mathrm{mg} / \mathrm{kg}$ cocaine the distribution was shifted to the right (Figure 3a and b). During the $30 \mathrm{~min}$ before and after injection with $20 \mathrm{mg} / \mathrm{kg}$ cocaine, the mean ( $\pm \mathrm{SD}$ ) locomotor activity was $2324 \pm 1829$ and $13090 \pm 4182 \mathrm{~cm}$, respectively. Dividing the postinjection distribution using the median score of $12450 \mathrm{~cm} / 30 \mathrm{~min}$ resulted in LCRs and HCRs with mean $( \pm S D)$ activity scores before injection of $2082 \pm 2163$ and $2565 \pm 1501 \mathrm{~cm} / 30 \mathrm{~min}$, respectively. After injection, LCRs and HCRs increased locomotor activity to $10140 \pm 4182$ and $16040 \pm 3811 \mathrm{~cm} / 30 \mathrm{~min}$, respectively. Although multiple component analysis (NOCOM) of the $30 \mathrm{~min}$ postinjection period did not indicate a twocomponent model, ANOVA revealed significant main effects of group and time $\left(\mathrm{F}_{1,18}=14.7, p<0.001\right.$ and $\mathrm{F}_{9,162}=79.6, \quad p<0.001$, respectively) and a significant group $\times$ time interaction $\left(\mathrm{F}_{9,162}=3.61, p<0.001\right)$. In addition, observational measures of behavior suggested that some of the distinctions between LCRs and HCRs that were observed after $10 \mathrm{mg} / \mathrm{kg}$ cocaine were also present after the $20 \mathrm{mg} / \mathrm{kg}$ dose. For example, HCRs exhibited more exploring and rearing than LCRs (Figure $4 \mathrm{c}$ and d), although differences were only statistically significant during one 15min interval. In contrast to the effects of $10 \mathrm{mg} / \mathrm{kg}$ cocaine, there were no longer differences between LCRs and HCRs in nonmovement periods or in head movement/sniffing (Figure $4 \mathrm{a}$ and $\mathrm{b}$ ). Furthermore, the higher dose of cocaine increased stereotypy in both groups (Figure 4c). Neither group had changes in grooming behavior (data not shown).

Unlike HCRs classified with $10 \mathrm{mg} / \mathrm{kg}$ cocaine, HCRs classified with $20 \mathrm{mg} / \mathrm{kg}$ cocaine had a greater response to the novel environment during the first $15 \mathrm{~min}$ they were in the open-field apparatus (Figure 3c). During this time period, HCRs traveled a total of $10028 \pm 1445 \mathrm{~cm}$, whereas LCRs traveled a total of $8493 \pm 1859 \mathrm{~cm}$. However, when rats were recharacterized as LRs and HRs based on their locomotor behavior during the first $30 \mathrm{~min}$ in the activity chamber, there was no difference in locomotor activation induced by $20 \mathrm{mg} / \mathrm{kg}$ cocaine (Figure $3 \mathrm{~d}$ ).

\section{Brain Levels of Cocaine}

To investigate the hypothesis that differences in brain levels of cocaine mediate the behavioral differences observed between LCRs and HCRs, we tested a separate group of rats in the open-field apparatus. These rats were killed $30 \mathrm{~min}$ after injection with $10 \mathrm{mg} / \mathrm{kg}$ cocaine so that drug levels in the dSTR and NAc could be determined at the time of maximal activation. In these rats, the median locomotor activity after cocaine was $8418 \mathrm{~cm} / 30 \mathrm{~min}$, with values (mean \pm SD) for LCRs and HCRs of $5554 \pm 1601$ and $12740 \pm 3048$, respectively. As shown in Table 1 , the concentration of cocaine in the dSTR was significantly higher by $8-12 \%$ than that measured in NAc. Although similar, small differences within each brain region were observed between LCRs and HCRs, these were not statistically significant. Analysis of the relationship between brain levels of cocaine and each rat's 
locomotor activity during the $30 \mathrm{~min}$ after injection revealed a small, positive correlation in the dSTR (Figure 5a) and NAc (Figure $5 \mathrm{~b}$ ) that was statistically significant only in the NAc.
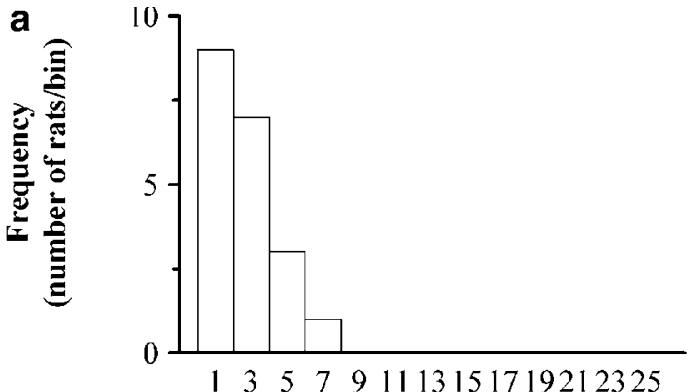

Distance Traveled $\left(x_{10}^{3} \mathrm{~cm} / 30 \mathrm{~min}\right)$

b

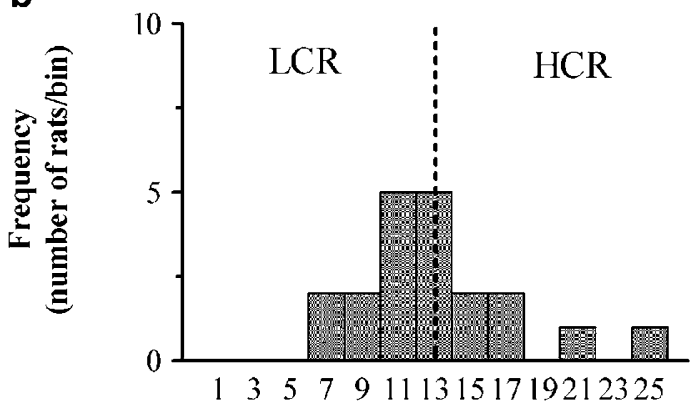

Distance Traveled (x $\left.10^{3} \mathrm{~cm} / 30 \mathrm{~min}\right)$

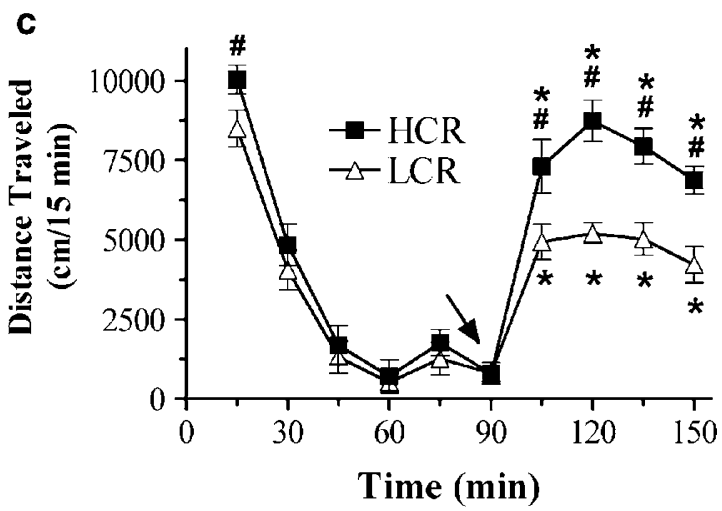

d

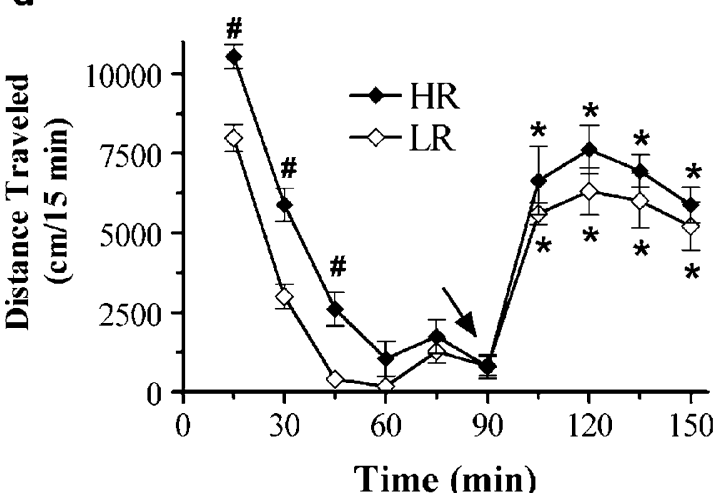

\section{Number and Affinity of DAT binding Sites}

We have previously shown that individual differences in locomotor activation after $10 \mathrm{mg} / \mathrm{kg}$ cocaine are closely related to the ability of the drug to inhibit DAT function (Sabeti et al, 2002). One possible explanation for this finding is the existence of different numbers or affinities of DATs or affinities of DAT for cocaine in LCRs, compared to HCRs. To test this hypothesis, we constructed $\left[{ }^{3} \mathrm{H}\right]$ WIN 35,428 saturation and cocaine competition binding curves using NAc membranes from LCRs and HCRs 7 days after their initial behavioral characterization with $10 \mathrm{mg} / \mathrm{kg}$ cocaine. This analysis, which supported a single-site binding model, indicated no statistically significant group differences in the number or affinity of DAT binding sites or in DAT affinity for cocaine (Table 2).

\section{Behavioral ReTest}

In order to determine the stability of our initial behavioral classification, rats were retested 7 days after their initial 10 or $20 \mathrm{mg} / \mathrm{kg}$ cocaine treatment. Animals remained in their home cage and did not undergo any drug or saline treatments between test and retest sessions. A total of 42 rats tested with $10 \mathrm{mg} / \mathrm{kg}$ cocaine on day 1 were retested on day 8 , with seven each of LCRs and HCRs tested with saline or cocaine $(10$ or $20 \mathrm{mg} / \mathrm{kg}$ ). All 20 rats given $20 \mathrm{mg} / \mathrm{kg}$ cocaine on day 1 were retested on day 8 with $20 \mathrm{mg} / \mathrm{kg}$ cocaine.

In the group of rats initially classified as LCRs or HCRs with $10 \mathrm{mg} / \mathrm{kg}$ cocaine, baseline locomotor activity for the $30 \mathrm{~min}$ prior to injection on day 8 was unchanged in LCRs $\left(t_{40}=0.992, p>0.05\right)$ but higher in HCRs $\left(t_{40}=3.43\right.$, $p<0.01)$, compared to the same period on test day 1 (Figure 6a). Specifically, this anticipatory locomotor response in HCRs was $230 \%$ higher than that observed on day 1. After saline (Figure 6b), locomotor activity in both LCRs and HCRs was confined to the period just after the injection, with the animals spending the remainder of the session moving only occasionally. Not surprisingly, observational analysis revealed that following saline injection on day 8 , the behavioral category with the greatest increase from cocaine-induced behavior on day 1 was nonmovement (Figure 7a). Scores for all other behavioral categories were decreased on day 8 after saline.

When injected with $10 \mathrm{mg} / \mathrm{kg}$ cocaine on the retest day, locomotor activation in LCRs initially characterized with this same dose was unchanged from day 1 (Figure 6c).

Figure 3 Individual differences in the locomotor activity of outbred, male Sprague-Dawley rats before and after injection of $20 \mathrm{mg} / \mathrm{kg}$ cocaine on test day I. Behavior was measured as described in Figure I. Frequency distributions of cumulative locomotor activity for the $30 \mathrm{~min}$ before and after injection are shown in (a) and (b) (dotted line = median; $12450 \mathrm{~cm} /$ $30 \mathrm{~min}$ ). (c) Mean \pm SEM locomotor responses of LCRs and HCRs over the course of the experiment ( $n=20 /$ group; arrow = time of injection). ${ }^{*} p<0.05$, within-group comparison to the 15 -min period before injection; $\#_{p<0.05}$, compared to LCRs in the same 15-min interval. (d) In rats recharacterized as either LRs or HRs based on their locomotion during their first $30 \mathrm{~min}$ in the open-field chamber, $20 \mathrm{mg} / \mathrm{kg}$ cocaine increased locomotor activity to the same extent in both groups. ${ }^{*} p<0.05$, withingroup comparison to the 15 -min period before injection; $p<0.05$, compared to LRs in the same 15-min interval. 


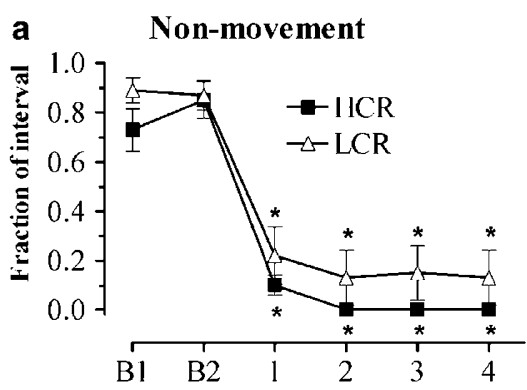

b Head movement/sniffing
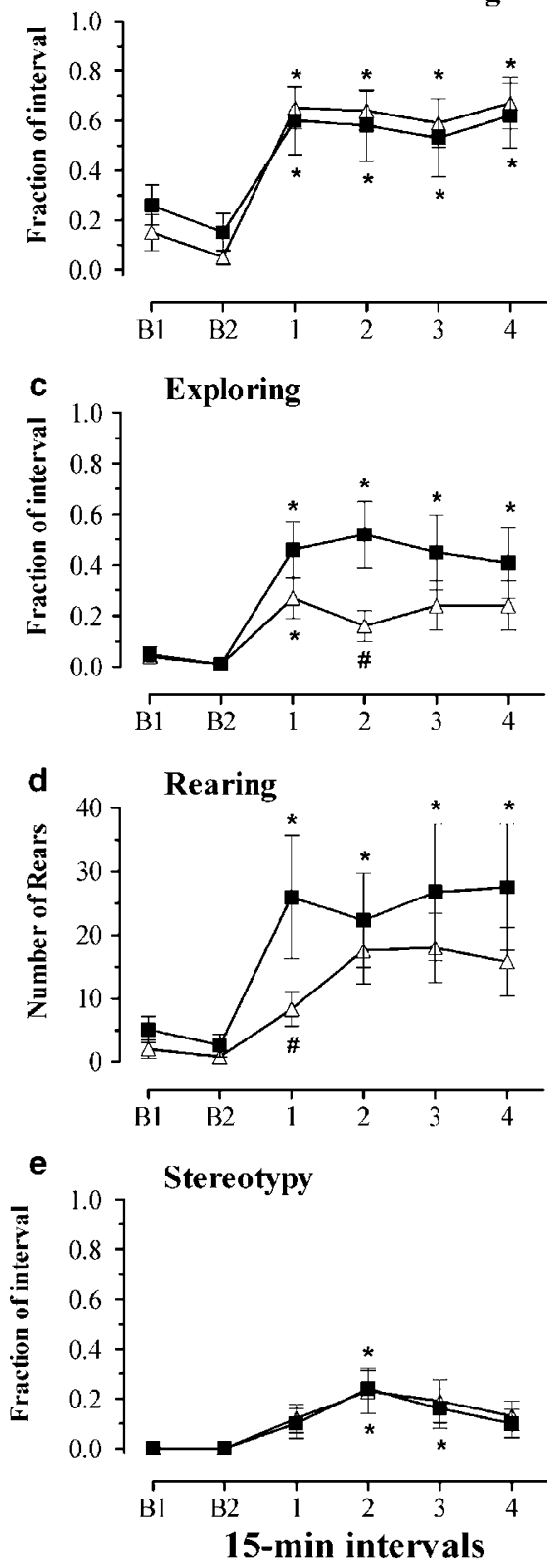

Figure 4 Observational analysis of behavior on test day I in LCRs and HCRs given $20 \mathrm{mg} / \mathrm{kg}$ cocaine (characterized in Figure 3). The 15-min intervals before (BI and $\mathrm{B} 2$ ) and after ( $1-4)$ drug injection are shown. Behaviors were scored as in Figure 2; $n=9$ each for LCRs and HCRs (two rats from Figure 3 were not scored due to technical problems). ${ }^{*} p<0.05$, within-group comparison to B2; ${ }^{\#} p<0.05$, compared to HCRs at the same postinjection interval.
Table I Concentrations of Cocaine in the Brains of LCRs and HCRs $30 \mathrm{~min}$ after Injection of $10 \mathrm{mg} / \mathrm{kg}$ Cocaine

\begin{tabular}{lcc}
\hline & dSTR (ng/mg tissue) & NAc (ng/mg tissue) \\
\hline LCRs $(n=13)$ & $1.48 \pm 0.15$ & $1.37 \pm 0.09 * *$ \\
HCRs $(n=13)$ & $1.67 \pm 0.08$ & $1.49 \pm 0.06 * *$ \\
\hline
\end{tabular}

Two-factor, repeated measures ANOVA indicated a statistically significant effect of brain region $\left(F_{1,24}=8.56, p<0.01\right)$, but no effect of group $\left(F_{1,24}=1.47\right.$, $p>0.05)$ and no interaction $\left(F_{1,51}=0.49, p>0.05\right)$. ** $p<0.01$ compared to dSTR.
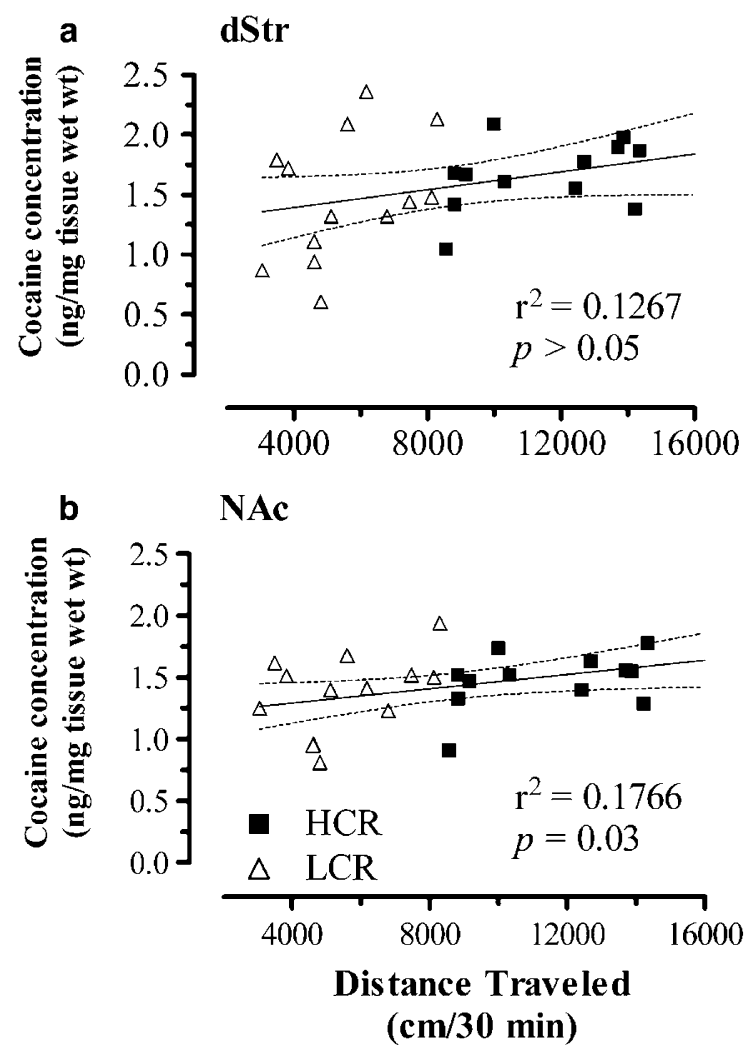

Figure 5 Relationship between cocaine-induced locomotor activity and drug concentration in dSTR (a) and NAc (b). The distance traveled refers to the total locomotor activity $(\mathrm{cm})$ for the $30 \mathrm{~min}$ after injection of $10 \mathrm{mg} /$ $\mathrm{kg}$ cocaine. For each brain region, linear regression fit $(-)$ and $95 \%$ confidence intervals (---) are shown. Statistical analysis revealed that the slope of the regression line was not significantly different from zero in dSTR $\left(F_{1,24}=3.48, p>0.05\right)$, but there was a significant, albeit small, relationship in the NAc $\left(F_{1,24}=5.15, p=0.03\right)$.

There were also no significant shifts in behavior from one category to another (Figure $7 \mathrm{~b}$ ). In contrast, cocaineinduced locomotor activation in HCRs was attenuated on day 8 and was not significantly different from the postinjection locomotor activity of LCRs (Figure 6c). In parallel to this decrease in locomotor activity, HCRs also exhibited significant decreases in exploring and rearing and increases in head movement/sniffing (Figure 7b). Compared to their activity after $10 \mathrm{mg} / \mathrm{kg}$ cocaine on day 1 , both LCRs and HCRs increased locomotor activity in response to $20 \mathrm{mg} / \mathrm{kg}$ cocaine on day 8 ; LCRs had the greatest relative increase in locomotion (Figure 6d). For the entire 60-min period after injection, cumulative locomotor activity in 
Table 2 Number and Affinity of DAT Binding Sites in Membranes of NAc from LCRs and HCRs Initially Classified with $10 \mathrm{mg} / \mathrm{kg}$

Cocaine

\begin{tabular}{lcc}
\hline & $\boldsymbol{K}_{\mathbf{i}}(\mathbf{n M})$ & $\begin{array}{c}\text { Bmax (pmol/mg } \\
\text { protein) }\end{array}$ \\
\hline Indirect saturation: ${ }^{3}$ H]WIN 35,428 & & \\
LCRs $(n=10)$ & $35.4 \pm 3.45$ & $5.67 \pm 0.80$ \\
HCRs $(n=9)$ & $36.7 \pm 1.72$ & $4.53 \pm 0.62$ \\
Competition of ${ }^{3}$ H]WIN 35,428: & & \\
Cocaine & $140 \pm 20.5$ & - \\
LCRs $(n=7)$ & $122 \pm 7.75$ & - \\
HCRs $(n=7)$ & \\
\hline
\end{tabular}

Student's t-test revealed no significant group differences in $K_{i}$ or $B_{\max }$ values $(p>0.05)$.

LCRs increased by $98 \%$, whereas in HCRs it increased by $32 \%$. There was no difference between the two groups in the maximal locomotor activity induced by $20 \mathrm{mg} / \mathrm{kg}$ cocaine (Figure 6d). The higher retest dose produced shifts in specific behaviors: nonmovement was decreased and exploring was increased in LCRs, whereas there was a trend toward increases in stereotypy in HCRs (Figure 7c). Rearing was increased, but not significantly, in both groups.

The behavior of rats classified as LCRs or HCRs with $20 \mathrm{mg} / \mathrm{kg}$ cocaine on day 1 and retested with this same dose on day 8 is shown in Figure 8. Baseline locomotor activity on day 8 significantly increased in HCRs initially classified with $10 \mathrm{mg} / \mathrm{kg}$ cocaine (see above); a similar trend was also observed in this group of HCRs $\left(t_{18}=1.96, p=0.08\right.$ Figure 8a). Cocaine-induced locomotor activation was comparable in this group of LCRs and HCRs initially classified with $20 \mathrm{mg} / \mathrm{kg}$ cocaine and retested with the same dose (Figure $8 \mathrm{~b}$ ). This similarity was due to an increase in cocaine-induced locomotion in LCRs. On day 8 compared to day 1 , the cumulative locomotor activity for the $60 \mathrm{~min}$ following $20 \mathrm{mg} / \mathrm{kg}$ cocaine was, on average, increased by $26 \%$ in LCRs, whereas it was unchanged over time in HCRs. Observational analysis of behavior also suggested that LCRs and HCRs were similar on day 8 (Figure $8 \mathrm{c}$ ). This was the result of within-group shifts in behavior compared to the initial test session. For example, on day 8, LCRs tended to exhibit less head movement/sniffing and more exploring and rearing.

\section{DISCUSSION}

Our laboratory recently characterized outbred, male Sprague-Dawley rats as LCRs or HCRs based on their locomotor

Figure 6 Results of behavioral retest on day 8 in rats classified as LCRs or HCRs with $10 \mathrm{mg} / \mathrm{kg}$ cocaine on day I. (a) Cumulative locomotor activity during the 30 -min baseline period on days I and 8 ( $n=2$ I/group). ** $p<0.0$ I, Student's t-test compared to day I (b-d) Locomotor scores from rats ( $n=7 /$ group for each treatment) pseudorandomly assigned to receive either saline or cocaine ( 10 or $20 \mathrm{mg} / \mathrm{kg}$; arrow = time of injection) on day 8 . Both the day I and day 8 scores are shown in each figure (dotted and solid lines, respectively). ${ }^{*} p<0.05$, within-group comparison to the I5min period before injection on test day 8; ${ }^{\#} p<0.05$, within-HCR comparison of day I to day 8 at the specified time interval; ${ }^{+} p<0.05$, within-LCR comparison of day I to day 8 at the specified time interval. activity after a single, i.p. injection of $10 \mathrm{mg} / \mathrm{kg}$ cocaine (Sabeti et al, 2002, 2003). Previous studies have emphasized individual differences in acute drug responses (eg Segal and Schuckit, 1983). However, our findings highlighted the DAT as a potentially important mediator of variation in cocaineinduced behavior. Here, we investigated whether the LCR/ HCR distinction could be generalized to a higher dose of
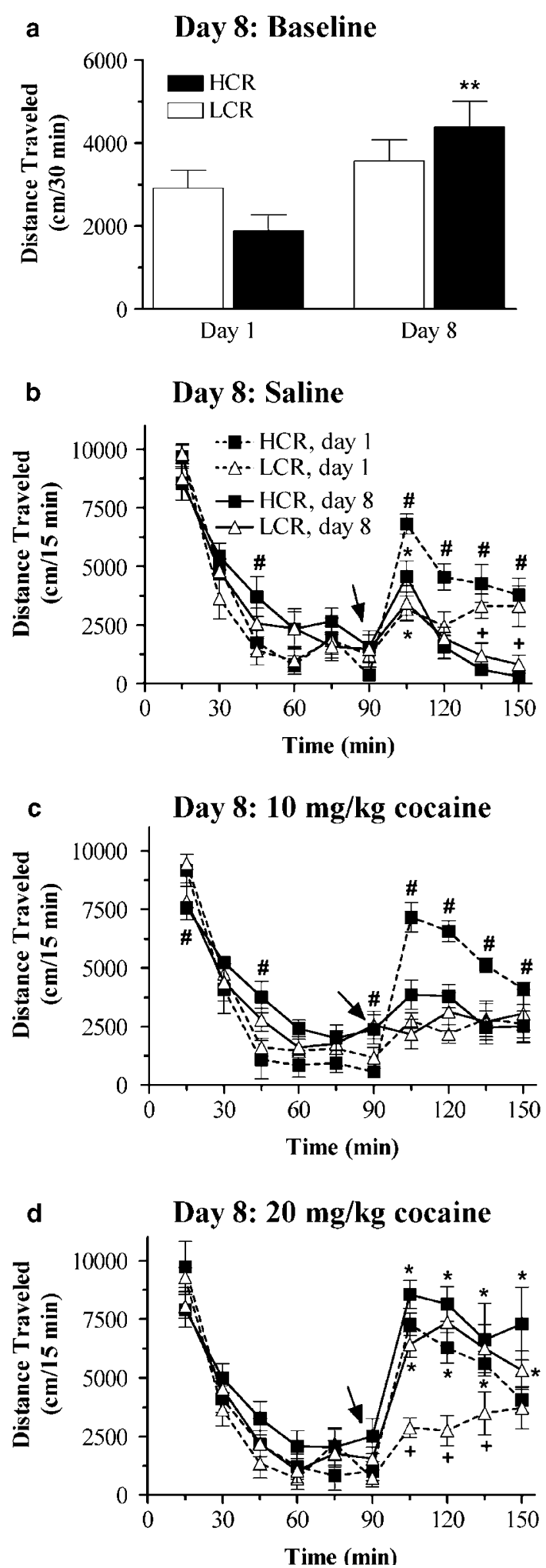

Neuropsychopharmacology 
a

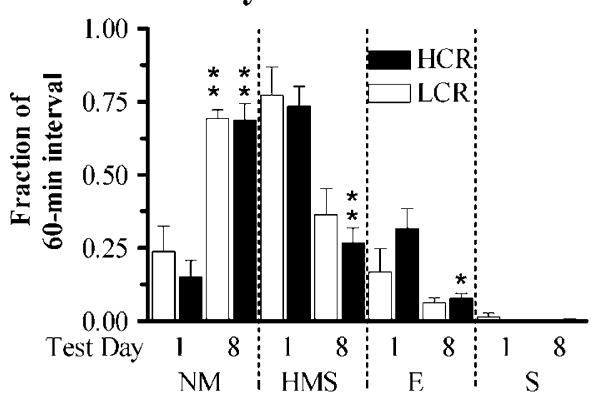

b

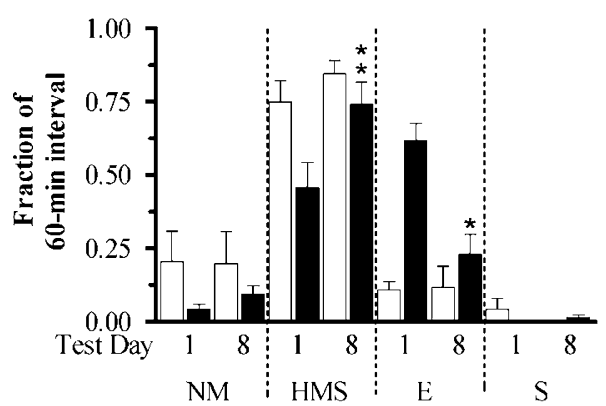

C

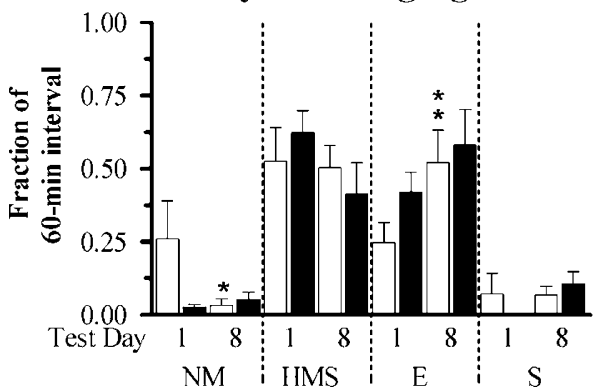

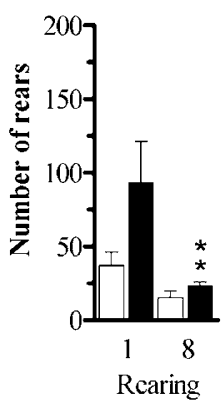
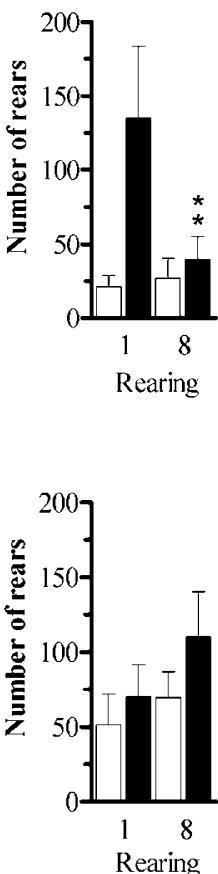

Figure 7 Comparison of different behavioral categories in LCRs and HCRs on day I after $10 \mathrm{mg} / \mathrm{kg}$ cocaine and on day 8 after saline (a), $10 \mathrm{mg} /$ $\mathrm{kg}$ (b) or $20 \mathrm{mg} / \mathrm{kg}$ cocaine (c). Data are from the same rats in Figure 6 and are presented as the fraction of the $60 \mathrm{~min}$ after injection that rats were engaged in nonmovement (NM), head movement/sniffing (HMS), exploring $(E)$, and stereotypy $(S)$. The exception was rearing, which is presented as the total number of rears after injection. Behaviors were scored as in Figure 2. $* p<0.05$ and ${ }^{*} * p<0.01$, compared to test day I within the respective group.

cocaine, if the behavioral disparity we observed with $10 \mathrm{mg} /$ $\mathrm{kg}$ cocaine is due to differences in cocaine pharmacokinetics among rats, whether differences in number and/or affinity of DAT binding sites or affinity of DAT binding sites for cocaine could account for the behavioral differences, and if the LCR/HCR classification was stable over time.

In the large sample of male Sprague-Dawley rats studied here, we found a wide range of cocaine-induced locomotor responses. The distribution of locomotor activity for the $30 \mathrm{~min}$ after injection with $10 \mathrm{mg} / \mathrm{kg}$ cocaine was Gaussian in nature, with prominent bimodal characteristics. In confirmation, multiple-component statistical analysis indicated the existence of low and high response elements (LCRs: 49\% weight; HCRs: $51 \%$ weight). Observational analysis indicated that LCRs were activated by this dose of

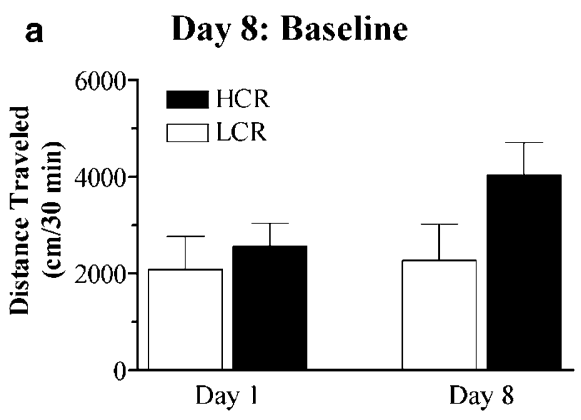

b

Day 8: $20 \mathrm{mg} / \mathrm{kg}$ cocaine

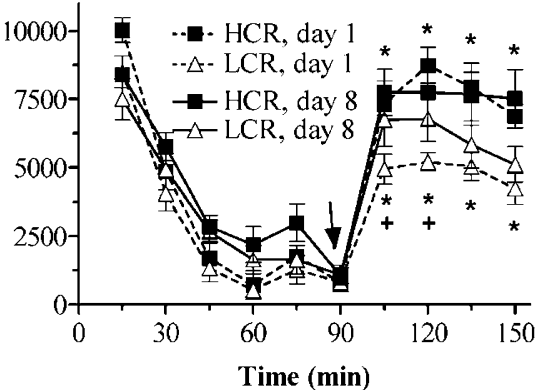

c Day 8: $20 \mathrm{mg} / \mathrm{kg}$ cocaine
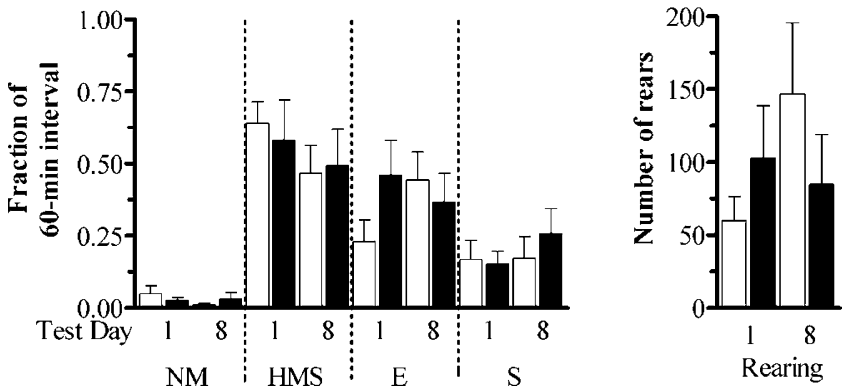

Figure 8 Results of behavioral retest on day 8 in rats initially classified as either LCRs or HCRs with $20 \mathrm{mg} / \mathrm{kg}$ cocaine on day I (see Figure 3). (a) Cumulative locomotor activity during the 30 -min baseline period on days I and 8 ( $n=10 /$ group). Locomotor activities on days I and 8 (dotted and solid lines, respectively; arrow $=$ time of injection; $n=10$ /group) and behavioral category comparisons for days I and 8 ( $n=9 /$ group; two rats were not scored due to technical problems) are shown in (b) and (c), respectively. ${ }^{*} p<0.05$, within-group comparison to the 15 -min period before injection on test day $8 ;{ }^{+} p<0.05$, within-LCR comparison of day I to day 8 at the specified time interval. In (c), behaviors were scored as in Figure 2 and abbreviations are defined as in Figure 7.

cocaine, but that their behavior was largely confined to head movements and sniffing. HCRs, in contrast, exhibited cocaine-induced increases in head movements/sniffing, exploring, and rearing. In a separate group of rats given $20 \mathrm{mg} / \mathrm{kg}$ cocaine, there was also a relatively broad range of locomotor activation, but there was less disparity in the behavior of LCRs compared to HCRs. In addition, HCRs from this group exhibited more baseline activity during their first $15 \mathrm{~min}$ in the open-field apparatus. This is unlikely to account for the group differences in behavioral activation observed after $20 \mathrm{mg} / \mathrm{kg}$ cocaine, however, since this enhanced 'novelty' response was no 
longer apparent during the subsequent time periods before injection.

Other groups have described similar individual differences in the behavioral responses to both amphetamine and cocaine, but these reports have focused largely on rats initially characterized as either low or high locomotor responders to a novel environment (Piazza et al, 1989; Hooks et al, 1991a; Bardo et al, 1996). When our sample of rats was recharacterized as LRs or HRs, their locomotor responses to $10 \mathrm{mg} / \mathrm{kg}$ cocaine differed only during the 15 min period after injection and their responses to $20 \mathrm{mg} / \mathrm{kg}$ cocaine were similar. This result is consistent with several reports emphasizing that novelty responses tend not to predict acute cocaine behavioral responsiveness, but instead are more predictive of behavioral sensitization after repeated cocaine treatment (Piazza et al, 1989; Hooks et al, 1991a; Cools and Gingras, 1998; but see Chefer et al, 2003). Further, it suggests that the LCR/HCR classification is distinct from one based on novelty responses and may provide another useful model for studying the mechanisms that underlie the relationship between acute and chronic drug effects.

The results of our HPLC experiments do not support differences in cocaine pharmacokinetics as an explanation for the disparate locomotor response to $10 \mathrm{mg} / \mathrm{kg}$ cocaine. We observed no statistically significant group differences in cocaine levels measured in either dSTR or NAc, although within the groups, there was significantly less cocaine (8$12 \%$ ) in the NAc compared to the dSTR. This regional concentration difference is not always observed after i.p. administration of cocaine (Javaid and Davis, 1993; Cass and Zahniser, 1993), and whether it impacts the behavioral effects of the drug is unclear. The tendency for HCRs to have higher cocaine levels in ASTR and NAc, compared with LCRs, is not likely to be the sole explanation for the higher degree of locomotor activation in the HCRs, since the locomotor activity of the subgroup of LCRs and HCRs used for the brain level analysis differed by more than two-fold. Furthermore, cocaine levels in dSTR and locomotor activity were not significantly correlated (Figure 3). There was a statistically significant relationship between NAc cocaine levels and activity, but it accounted for only $\sim 18 \%$ of the variability and, thus, is not likely to explain the large individual variation in cocaine-induced behavior. Our findings are consistent with those showing no difference in brain cocaine levels between LRs and HRs, despite their dissimilar i.v. cocaine self-administration behavior (Piazza et al, 2000). Likewise, inbred mice strains differ significantly in cocaine-induced locomotor activity, but not in brain cocaine levels (Ruth et al, 1988).

Variation in the basal number and/or affinity of DAT binding sites could explain differences in cocaine-induced locomotor activity between LCRs and HCRs. In fact, both number of DAT binding sites and DAT affinity for $\left[{ }^{3} \mathrm{H}\right]$ WIN 35,428 are increased in the NAc of HRs compared to LRs (Chefer et al, 2003). However, in the radioligand binding studies described here, we found no significant differences between LCRs and HCRs in the number or affinity of DAT binding sites in NAc. Furthermore, the affinity of DAT for cocaine was also not different. It is important to note that these experiments were conducted with crude membranes and therefore reflect the total cellular content of DAT in
NAc. They do not differentiate nonfunctional and functional populations of DAT located intracellularly and at the neuronal membrane, respectively. The possibility that cocaine induces rapid changes in DAT cell surface expression via trafficking and that these changes vary in LCRs compared to HCRs may contribute to the behavioral differences observed between the two groups. Interestingly, recent reports suggest that in vitro exposure to cocaine rapidly increases DAT function via increases in cell-surface expression of DAT (Daws et al, 2002; Little et al, 2002). If there were differences in basal trafficking of DAT in LCRs compared to HCRs, they would likely be exaggerated by exposure to cocaine. Alternatively, potential differences in DA release between LCRs and HCRs may be revealed in the presence of cocaine.

Retesting the behavior of LCRs and HCRs after 7 days had elapsed without additional treatment was designed to assess the consistency of the initial behavioral classification and to evaluate further the effects of a higher dose of cocaine. Rats initially classified as LCRs or HCRs with $10 \mathrm{mg} / \mathrm{kg}$ cocaine were thus retested on day 8 with saline or cocaine (10 or $20 \mathrm{mg} / \mathrm{kg}$ ) and those initially classified with $20 \mathrm{mg} / \mathrm{kg}$ cocaine were retested on day 8 with $20 \mathrm{mg} / \mathrm{kg}$ cocaine. Before injection on day 8 , HCRs exhibited increased locomotor activity, compared to the same time period on day 1. This behavior, which appeared to be related to anticipation of the injection and was not observed in LCRs, may indicate that HCRs are more responsive to conditioned drug effects. Notably, the development and expression of behavioral sensitization to psychostimulants is influenced strongly by the discriminative stimulus properties of these drugs (Hinson and Poulos, 1981; Anagnostaras and Robinson, 1996).

After saline, locomotor activity was decreased in both LCRs and HCRs, as behavior consisted mostly of prolonged periods of nonmovement. Cocaine, in contrast, had unique effects in LCRs, compared to HCRs, depending on the dose tested. When given $10 \mathrm{mg} / \mathrm{kg}$ cocaine on day 1 and $20 \mathrm{mg} / \mathrm{kg}$ on day 8, LCRs and HCRs were activated to a similar extent by the higher dose. LCRs, however, had the greater relative increase in behavior compared to day 1 . These results argue against a ceiling effect precluding the observation of cocaine-induced activity in LCRs classified on day 1 with $10 \mathrm{mg} / \mathrm{kg}$ cocaine.

When given $10 \mathrm{mg} / \mathrm{kg}$ cocaine on both days 1 and 8 , neither LCRs nor HCRs increased locomotor activity relative to baseline. This change in behavior over time, which was most dramatic for HCRs and was paralleled by decreases in exploring and rearing and increases in head movement/sniffing, suggests that both LCRs and HCRs became tolerant to the locomotor activating effects of this dose. This finding was unexpected, given the reports that higher brain cocaine levels are achieved by a second i.p. injection of cocaine administered as long as 7 days later (Cass and Zahniser, 1993; Pettit and Pettit, 1994). Furthermore, this observation also contrasts with repeated administration of $10 \mathrm{mg} / \mathrm{kg}$ cocaine for 7 days, which induces behavioral sensitization in LCRs and a constant, high level of activity in HCRs (Sabeti et al, 2003). When rats were given $20 \mathrm{mg} / \mathrm{kg}$ cocaine on both days 1 and 8 , both LCRs and HCRs increased their behavior relative to baseline. In this case, LCRs were more responsive to the same dose on 
the retest day, while the behavior of HCRs was relatively unchanged over time. It appears that, at least in LCRs, a single administration of $20 \mathrm{mg} / \mathrm{kg}$ cocaine leads to an enhanced behavioral response upon retesting. The ability of a single drug exposure to produce neurochemical and/or behavioral sensitization following at least 7 days of no treatment has been described previously for both cocaine (Guan et al, 1985; Peris and Zahniser, 1987, 1989; Keller et al, 1992) and amphetamine (Antelman et al, 1980; Robinson et al, 1982; Vanderschuren et al, 1999). However, the results of the present study emphasize that the ability of a single injection of cocaine to induce locomotor sensitization may depend not only on the dose of cocaine but also on the animal's acute behavioral response to the drug. In fact, a rat's initial locomotor response to $10 \mathrm{mg} / \mathrm{kg}$ cocaine predicts whether it will express behavioral sensitization after repeated cocaine treatment (Sabeti et al, 2003). Our findings also indicate that, whereas there are robust individual differences in the acute response to cocaine (eg Cass et al, 1993; Sabeti et al, 2002), the LCR/HCR classification is not stable over time. This is due, perhaps, to changes in contextual influences on behavior. Although it is not clear how these influences modulate the response to cocaine, they have been noted before. For example, LRs and HRs exhibit differences in lever-pressing and nose-poking behavior that are evident when cocaine is available, but not when saline or cue-only conditions are instituted (Marinelli and White, 2000; Piazza et al, 1990, 2000).

While DA and the DAT likely play an important role in individual responses to cocaine, other possibilities exist. For example, LCRs and HCRs may differ in norepinephrine and serotonin systems. These systems are known to be critical for behavioral activation both before and after drug exposure (Feenstra et al, 2000; Uhl et al, 2002) and appear to be important for psychostimulant reward (Robinson and Berridge, 1993; Rocha et al, 1998; Sora et al, 2001) and behavioral sensitization ( $\mathrm{Xu}$ et al, 2000; Walsh and Cunningham, 1997). Variations in endogenous glucocorticoid and/or gonadal hormones may also influence the acute, locomotor response to cocaine in LCRs and HCRs. Adrenalectomy, which suppresses the effects of glucocorticoids such as corticosterone, attenuates cocaine selfadministration and its locomotor-stimulant properties (Marinelli et al, 1997a,b), whereas administration of corticosterone enhances the locomotor and reinforcing properties of both cocaine and amphetamine (Piazza et al, 1991a; Deroche et al, 1992; Cador et al, 1993). Removing the influence of gonadal hormones by castration in male rats also leads to a reduction in cocaine-induced locomotor behavior (Chin et al, 2002). It will be important for future studies investigating mechanisms underlying LCR/HCR behavioral differences to address more of these potential explanations.

Cocaine activates a wide range of behaviors in rats, but there are significant individual differences in the degree to which they are altered. In outbred, male Sprague-Dawley rats, these differences are closely related to cocaine's ability to inhibit DAT function (Sabeti et al, 2002). The results presented here rule out several potential explanations for the individual differences in cocaine-induced behavior and cocaine inhibition of DAT activity, suggest explanations involving $\mathrm{DA}$ and non-DA systems that remain to be explored, and emphasize the influence of a single cocaine exposure on subsequent behavioral responses to the drug. Ultimately, identifying the defining characteristics of LCRs and HCRs should increase our understanding of why individuals can differ so markedly in cocaine-induced behavioral activation.

\section{ACKNOWLEDGEMENTS}

This work was supported by the National Institutes of Health Grants AA 07464, DA 04216, DA 15050, and NS 07083. We thank Eric A Horne and Elizabeth Stubblefield for assistance with the behavioral studies for this project.

\section{REFERENCES}

Anagnostaras SG, Robinson TE (1996). Sensitization to the psychomotor stimulant effects of amphetamine: modulation by associative learning. Behav Neurosci 110: 1397-1414.

Antelman SM, Eichler AJ, Black CA, Kocan D (1980). Interchangeability of stress and amphetamine in sensitization. Science 207: 329-331.

Bardo MT, Donohew RL, Harrington NG (1996). Psychobiology of novelty seeking and drug seeking behavior. Behav Brain Res 77: 23-43.

Benuck M, Lajtha A, Reith ME (1987). Pharmacokinetics of systemically administered cocaine and locomotor stimulation in mice. J Pharmacol Exp Ther 243: 144-149.

Bradberry CW, Gruen RJ, Berridge CW, Roth RH (1991). Individual differences in behavioral measures: correlations with nucleus accumbens dopamine measured by microdialysis. Pharmacol Biochem Behav 39: 877-882.

Bradford MM (1976). A rapid and sensitive method for the quantification of microgram quantities of protein utilizing the principle of protein-dye binding. Anal Biochem 72: 248-254.

Cador M, Dulluc J, Mormede P (1993). Modulation of the locomotor response to amphetamine by corticosterone. Neuroscience 56: 981-988.

Camp DM, Robinson TE (1988). Susceptibility to sensitization. I. Sex differences in the enduring effects of chronic D-amphetamine treatment on locomotion, stereotyped behavior and brain monoamines. Behav Brain Res 30: 55-68.

Cass WA, Gerhardt GA, Gillespie K, Curella P, Mayfield RD, Zahniser NR (1993). Reduced clearance of exogenous dopamine in rat nucleus accumbens, but not in dorsal striatum, following cocaine challenge in rats withdrawn from repeated cocaine administration. J Neurochem 61: 273-283.

Cass WA, Zahniser NR (1993). Cocaine levels in striatum and nucleus accumbens: augmentation following challenge injection in rats withdrawn from repeated cocaine administration. Neurosci Lett 152: 177-180.

Chefer VL, Zakharova I, Shippenberg TS (2003). Enhanced responsiveness to novelty and cocaine is associated with decreased basal dopamine uptake and release in the nucleus accumbens: quantitative microdialysis in rats under transient conditions. J Neurosci 23: 3076-3084.

Chin J, Sternin O, Wu HB, Burrell S, Lu D, Jenab S et al (2002). Endogenous gonadal hormones modulate behavioral and neurochemical responses to acute and chronic cocaine administration. Brain Res 945: 123-130.

Cools AR, Gingras MA (1998). Nijmegen high and low responders to novelty: a new tool in the search after the neurobiology of drug abuse liability. Pharmacol Biochem Behav 60: 151-159.

Daws LC, Callaghan PD, Moron JA, Kahlig KM, Shippenberg TS, Javitch JA et al (2002). Cocaine increases dopamine uptake and 
cell surface expression of dopamine transporters. Biochem Biophys Res Commun 290: 1545-1550.

DeBlasi A, O’Reilly K, Motulsky HJ (1989). Calculating receptor number from binding experiments using same compound as radioligand and competitor. Trends Pharmacol Sci 10: 227-229.

de Wit H, Uhlenhuth EH, Johanson CE (1986). Individual differences in the reinforcing and subjective effects of amphetamine and diazepam. Drug Alcohol Depend 16: 341-360.

Deminiere JM, Piazza PV, Le Moal M, Simon H (1989). Experimental approach to individual vulnerability to psychostimulant addiction. Neurosci Biobehav Rev 13: 141-147.

Deroche V, Piazza PV, Maccari S, Le Moal M, Simon H (1992). Repeated corticosterone administration sensitizes the locomotor response to amphetamine. Brain Res 584: 309-313.

DeSousa NJ, Bush DE, Vaccarino FJ (2000). Self-administration of intravenous amphetamine is predicted by individual differences in sucrose feeding in rats. Psychopharmacology (Berl) 148: $52-58$.

Guan LC, Robinson TE, Becker JB (1985). Sensitization of rotational behavior produced by a single exposure to cocaine. Pharmacol Biochem Behav 22: 901-903.

Feenstra MG, Botterblom MH, Mastenbroek S (2000). Dopamine and noradrenaline efflux in the prefrontal cortex in the light and dark period: effects of novelty and handling and comparison to the nucleus accumbens. Neuroscience 100: 741-748.

Fray PJ, Sahakian BJ, Robbins TW, Koob GF, Iversen SD (1980). An observational method for quantifying the behavioural effects of dopamine agonists: contrasting effects of D-amphetamine and apomorphine. Psychopharmacology (Berl) 69: 253-259.

Hebert MA, Larson GA, Zahniser NR, Gerhardt GA (1999). Agerelated reductions in $\backslash\{3 \mathrm{H} \backslash\} W I N 35,428$ binding to the dopamine transporter in nigrostriatal and mesolimbic brain regions of the Fischer 344 rat. J Pharmacol Exp Ther 288: 1334-1339.

Hinson RE, Poulos CX (1981). Sensitization to the behavioral effects of cocaine: modification by Pavlovian conditioning. Pharmacol Biochem Behav 15: 559-562.

Hooks MS, Jones GH, Smith AD, Neill DB, Justice Jr JB (1991a). Individual differences in locomotor activity and sensitization. Pharmacol Biochem Behav 38: 467-470.

Hooks MS, Jones GH, Smith AD, Neill DB, Justice Jr JB (1991b). Response to novelty predicts the locomotor and nucleus accumbens dopamine response to cocaine. Synapse 9: 121-128.

Hooks MS, Juncos JL, Justice Jr JB, Meiergerd SM, Povlock SL, Schenk JO et al (1994). Individual locomotor response to novelty predicts selective alterations in D1 and D2 receptors and mRNAs. J Neurosci 14: 6144-6152.

Javaid JI, Davis JM (1993). Cocaine disposition in discrete regions of rat brain. Biopharm Drug Dispos 14: 357-364.

Keller RW, Maisonneuve IM, Carlson JN, Glick SD (1992). Withinsubject sensitization of striatal dopamine release after a single injection of cocaine: an in vivo microdialysis study. Synapse 11: 28-34.

Little KY, Elmer LW, Zhong H, Scheys JO, Zhang L (2002). Cocaine induction of dopamine transporter trafficking to the plasma membrane. Mol Pharmacol 61: 436-445.

Marinelli M, Rouge-Pont F, De Jesus-Oliveira C, Le Moal M, Piazza PV (1997a). Acute blockade of corticosterone secretion decreases the psychomotor stimulant effects of cocaine. Neuropsychopharmacology 16: 156-161.

Marinelli M, Rouge-Pont F, Deroche V, Barrot M, De Jesus-Oliveira C, Le Moal M et al (1997b). Glucocorticoids and behavioral effects of psychostimulants. I: locomotor response to cocaine depends on basal levels of glucocorticoids. J Pharmacol Exp Ther 281: $1392-1400$.

Marinelli M, White FJ (2000). Enhanced vulnerability to cocaine self-administration is associated with elevated impulse activity of midbrain dopamine neurons. J Neurosci 20: 8876-8885.
Mayfield RD, Larson G, Zahniser NR (1992). Cocaine-induced behavioral sensitization and D1 dopamine receptor function in rat nucleus accumbens and striatum. Brain Res 573: 331-335.

Ott J (1979). Detection of rare major genes in lipid levels. Hum Genet 51: 79-91.

Peris J, Zahniser NR (1987). One injection of cocaine produces a long-lasting increase in $\left[{ }^{3} \mathrm{H}\right]$-dopamine release. Pharmacol Biochem Behav 27: 533-535.

Peris J, Zahniser NR (1989). Persistent augmented dopamine release after acute cocaine requires dopamine receptor activation. Pharmacol Biochem Behav 32: 71-76.

Pettit HO, Pettit AJ (1994). Disposition of cocaine in blood and brain after a single pretreatment. Brain Res 651: 261-268.

Piazza PV, Deminiere JM, Le Moal M, Simon H (1989). Factors that predict individual vulnerability to amphetamine self-administration. Science 245: 1511-1513.

Piazza PV, Deminiere JM, Maccari S, Mormede P, Le Moal M, Simon H (1990). Individual reactivity to novelty predicts probability of amphetamine self-administration. Behav Pharmacol 1: 339-345.

Piazza PV, Deroche-Gamonent V, Rouge-Pont F, Le Moal M (2000). Vertical shifts in self-administration dose-response functions predict a drug-vulnerable phenotype predisposed to addiction. J Neurosci 20: 4226-4232.

Piazza PV, Le Moal ML (1996). Pathophysiological basis of vulnerability to drug abuse: role of an interaction between stress, glucocorticoids, and dopaminergic neurons. Annu Rev Pharmacol Toxicol 36: 359-378.

Piazza PV, Maccari S, Deminiere JM, Le Moal M, Mormede P, Simon H (1991a). Corticosterone levels determine individual vulnerability to amphetamine self-administration. Proc Natl Acad Sci USA 88: 2088-2092.

Piazza PV, Rouge-Pont F, Deminiere JM, Kharoubi M, Le Moal M, Simon H (1991b). Dopaminergic activity is reduced in the prefrontal cortex and increased in the nucleus accumbens of rats predisposed to develop amphetamine self-administration. Brain Res 567: 169-174.

Pierce RC, Bell K, Duffy P, Kalivas PW (1996). Repeated cocaine augments excitatory amino acid transmission in the nucleus accumbens only in rats having developed behavioral sensitization. J Neurosci 16: 1550-1560.

Post RM, Weiss SR, Pert A (1988). Cocaine-induced behavioral sensitization and kindling: implications for the emergence of psychopathology and seizures. Ann N Y Acad Sci 537: 292-308.

Robinson TE (1988). Stimulant drugs and stress: factors influencing individual differences in the susceptibility to sensitization. In: Kalivas PW, Barnes C (eds). Sensitization of the Nervous System. Telford Press: Caldwell, NJ. pp 145-173.

Robinson TE, Becker JB, Presty SK (1982). Long-term facilitation of amphetamine-induced rotational behavior and striatal dopamine release produced by a single exposure to amphetamine: sex differences. Brain Res 253: 231-241.

Robinson TE, Berridge KC (1993). The neural basis of drug craving: an incentive-sensitization theory of addiction. Brain Res Brain Res Rev 18: 247-291.

Rocha BA, Fumagalli F, Gainetdinov RR, Jones SR, Ator R, Giros B et al (1998). Cocaine self-administration in dopamine-transporter knockout mice. Nat Neurosci 1: 132-137.

Ruth JA, Ullman EA, Collins AC (1988). An analysis of cocaine effects on locomotor activities and heart rate in four inbred mouse strains. Pharmacol Biochem Behav 29: 157-162.

Sabeti J, Gerhardt GA, Zahniser NR (2002). Acute cocaine differentially alters accumbens and striatal dopamine clearance in low and high cocaine locomotor responders: behavioral and electrochemical recordings in freely moving rats. J Pharmacol Exp Ther 302: 1201-1211.

Sabeti J, Gerhardt GA, Zahniser NR (2003). Individual differences in cocaine-induced locomotor sensitization in low and high 
cocaine locomotor-responding rats are associated with differential inhibition of dopamine clearance in nucleus accumbens. $J$ Pharmacol Exp Ther 305: 180-190.

Segal DS, Kuczenski R (1987). Individual differences in responsiveness to single and repeated amphetamine administration: behavioral characteristics and neurochemical correlates. $J$ Pharmacol Exp Ther 242: 917-926.

Segal DS, Schuckit MA (1983). Animal models of stimulantinduced psychosis. In: Creese I (ed). Stimulants: Neurochemical, Behavioral, and Clinical Perspectives. Raven Press: New York. pp 131-167.

Sora I, Hall FS, Andrews AM, Itokawa M, Li XF, Wei HB et al (2001). Molecular mechanisms of cocaine reward: combined dopamine and serotonin transporter knockouts eliminate cocaine place preference. Proc Natl Acad Sci USA 98: 5300-5305.
Differences in cocaine-induced locomotor activity

JM Gulley et allM Gulley et al

Uhl GR, Hall FS, Sora I (2002). Cocaine, reward, movement and monoamine transporters. Mol Psychiatry 7: 21-26.

Vanderschuren LJ, Schmidt ED, De Vries TJ, Van Moorsel CAP, Tilders FJH, Schoffeimeer ANM (1999). A single exposure to amphetamine is sufficient to induce long-term behavioral, neuroendocrine, and neurochemical sensitization in rats. $J$ Neurosci 19: 9579-9586.

Walsh SL, Cunningham KA (1997). Serotonergic mechanisms involved in the discriminative stimulus, reinforcing and subjective effects of cocaine. Psychopharmacology (Berl) 130: 41-58.

Xu F, Gainetdinov RR, Wetsel WC, Jones SR, Bohn LM, Miller GW et al (2000). Mice lacking the norepinephrine transporter are supersensitive to psychostimulants. Nat Neurosci 3: $465-471$. 